\title{
Identification of interspecific hybrid between Jatropha curcas $\times$ $J$. integerrima using morphological and molecular markers
}

\author{
DARMAWAN SAPTADI ${ }^{1, \vartheta}$, NUR ASBANI ${ }^{2}$, BAMBANG HELIYANTO ${ }^{2}$, ASEP SETIAWAN $^{3}$, SUDARSONO $^{3, v}$ \\ ${ }^{1}$ Plant Breeding Laboratory, Department of Agronomy, Faculty of Agriculture, Universitas Brawijaya. Jl. Veteran, Malang 65145, East Java, Indonesia, \\ Tel.: +62-341-551665, "email: darmawansaptadi@gmail.com \\ ${ }^{2}$ Indonesian Sweetener and Fiber Crops Research Institute. Jl. Raya Karangploso PO BOX 199, Malang 65152, East Java, Indonesia. \\ ${ }^{3}$ Department of Agronomy and Horticulture, Faculty of Agriculture, Institut Pertanian Bogor. Jl. Meranti, Kampus IPB Dramaga, Bogor 16680, West \\ Java, Indonesia. Tel./fax.: +62-251-8629353, "email: s_sudarsono@ymail.com
}

Manuscript received: 20 December 2019. Revision accepted: 27 January 2020

\begin{abstract}
Saptadi D, Asbani N, Heliyanto B, Setiawan A, Sudarsono. 2020. Identification of interspecific hybrid between Jatropha curcas $x$ J. integerrima using morphological and molecular markers. Biodiversitas 21: 814-823. Eight $\mathrm{F}_{1}$ progenies derived from Jatropha curcas $\times J$. integerrima hybridizations were evaluated for their morphological characters and using RAPD, ISSR and SSR markers. Morphological variations among the hybrids were limited and they were intermediate between the Jatropha parents. The eight $F_{1}$ progenies derived from $J$. curcas $\times J$. integerrima hybridizations were most probably the interspecific $F_{1}$ hybrids. The confirmed identity of the progenies as interspecific hybrids between $J$. curcas $\times J$. integerrima was based on the presence of several phenotypic characters from both parents in the F1 progenies and by similarity of the molecular marker banding patterns among the parents and the $\mathrm{F}_{1}$ progenies. Among the evaluated molecular markers, the ISSR primers and the majority of either RAPD and SSR primers were not able to generate marker for confirming the identity of $\mathrm{F}_{1}$ progenies as interspecific hybrids between $J$. curcas $\times$ J. integerrima. However, the RAPD primer OPC 10 and the SSR primers AF469003, EU099522 and EU586348 were able to generate polymorphic markers in the Jatropha parents and their $\mathrm{F}_{1}$ progenies. Therefore, these four primers were able to generate usable markers for confirming the identity of $F_{1}$ progenies as interspecific hybrids between $J$. curcas $\times J$. integerrima. The evaluated interspecific $\mathrm{F}_{1}$ progenies are potentially useful to increase genetic diversity of $J$. curcas and support its breeding program.
\end{abstract}

Keywords: $F_{1}$ interspecific, microsatellite, molecular marker, morphological variation

\section{INTRODUCTION}

Breeding activities require the presence of high genetic diversity for the targetted characters (Acquaah 2007) and for other supporting characters. Physic nut (Jatropha curcas) is a perennial crop (Raju and Ezradanam 2002). Compare to annual crops, new cultivar development for $J$. curcas requires more time (Divakara et al. 2010). On the other hand, new varieties having high oil content, yield and other desirable characters are still a priority for J. curcas breeding. Increased in $J$. curcas yield may be achieved through improving agronomic traits, resistance to biotic and abiotic stresses and developing better seed oil quality (Heller 1996). Although it needs some improvement, the yield potential of Indonesian $J$. curcas genotypes is relatively high (Hartati et al. 2009; Yi et al. 2010; Hartati et al. 2012).

Unfortunately, a report has also indicated that Indonesian $J$. curcas genetic diversity was low (Saptadi et al. 2017). Moreover, J. curcas breeding activities using such a narrow genetic base will not be efficient since the genetic gain for each breeding cycle will be low (Acquaah 2007). Therefore, activities to increase genetic diversity of Indonesian $J$. curcas collections should be beneficial. One such endeavor can be done by using interspecific hybrid among Jatropha species (Dhillon et al. 2009). Interspecific hybrids are used to increase genetic variation in many crops Gomes et al. 2014; Subroto et al. 2018; Banjanac et al. 2019). Hence, increase genetic diversity of $J$. curcas may be done by introducing desirable characters from other Jatropha species (Dhillon et al. 2009).

Jatropha curcas has a soft stem which makes the crop sensitive to waterlogging and root rot disease (Dhillon et al. 2009). J. curcas is also susceptible to both shoots infecting mites (Eriophyid and Polyphagotarsonemus latus) and thrips (Selenothrips rubrocinctus and Rhipiphorothrips cruentatus) (Asbani 2008). On the other hand, $J$. integerrima (the Jatropha species grown as an ornamental plant) has the tolerance to low temperature, resistance to stem rot disease, very resistance to leaf-eating caterpillar, and sturdy inflorescence characters (Lakshminarayana and Sujatha 2001). Asbani (2008) also reported that $J$. integerrima was probably resistant to shoot mites and thrips. The $J$. integerrima seeds also contain a high level of linoleic acid which affects oil quality (Rao and Lakshminarayana 1987). Therefore, J. integerrima may be used as the source of desirable characters for an interspecific hybridization with $J$. curcas (Dhillon et al. 2009).

Interspecific hybrid production is not an easy task since many constrain hamper the production of the hybrids such as sexual incompatibilities which limit the hybridization success, embryo abortion, low progeny quantity, and sterile hybrid plants (Van Tuyl 1997; Kaneko and Bang 2014). 
Moreover, identification of the true-to-type interspecific hybrid plants may not be an easy task since the hybrid seedlings may have similar morphologies than those of the self progenies (Thomasset et al. 2011). Grow out test (GOT) has been widely used to identify the interspecific hybrid progenies (Alam et al. 2015; Pattanaik et al. 2018) and it includes planting of the putative hybrid seed progenies, observing their morphological characters, and selecting progenies having the combined characters of both male and female parents. Such approach is timeconsuming, expensive and requires extensive resources (Wu et al. 2010), especially for such perennial crops as the Jatropha species. The GOT approach is also sensitive to environmental bias which reduces its effectiveness (Moose and Mumm 2008). Other studies proposed isoenzyme analysis as an effective alternative method (Ronis et al. 1990; Hirose et al. 1993). However, the presence of polymorphic isozyme banding patterns in closely related species is limited ( $\mathrm{Wu}$ et al. 2010). Therefore, the evaluation of other more sensitive methods to distinguish progenies of Jatropha interspecific hybrids is necessary and DNA-based markers may be the desired alternative methods (Spooner et al. 2005). Moreover, the DNA based markers may be used to select out undesirable progenies as early as at the seedling stage (Dhillon et al. 2009). Therefore, early identification of the interspecific hybrid progenies is possible.

Dhillon et al. (2009) used RAPD markers to identify progenies of the inter-specific hybrid between $J$. curcas and $J$. integerrima. The RAPD markers have also been used to identify progenies derived from hybridization of Passiflora (Conceição et al. 2011), Chrysanthemum (Huang et al. 2000), and Mentha (Shasany et al. 2005). Another alternative DNA marker such as simple sequence repeat (SSR) markers has also been used to identify hybrid progenies of Helianthus (Iqbal et al. 2011), corn (Wu et al. 2010), walnut (Pollegioni et al. 2009), and peanut (Gomez et al. 2008).

In earlier research (Asbani 2008), an array of putative interspecific hybrid progenies has been produced by intercrossing Indonesian $J$. curcas accessions to $J$. integerrima. The limited number of progenies formed from interspecific crossing can be due to incompatibility between the two species (Pershina and Trubacheeva 2017). Moreover, the putative interspecific hybrid progenies were morphologically closely related to the female $J$. curcas parent (Asbani 2008). Therefore, the DNA based markers may be used to confirm true identities of the putative Jatropha interspecific hybrids.

The aims of this research were to evaluate morphological variations among putative interspecific hybrid progenies between $J$. curcas $\times J$. integerrima and establish methods for identifying putative hybrids progenies using a combination of the SSR, RAPD, and ISSR markers. The identified interspecific hybrid may then be used to widen the genetic diversity of the existing $J$. curcas in Indonesia. Moreover, the availability of effective DNA based markers for interspecific hybrid identification may be beneficial for supporting future J. curcas breeding program using the interspecific hybrid progenies.

\section{MATERIALS AND METHODS}

\section{Plant materials and morphological characterization}

All plant materials used in this research were from Indonesian Sweetener and Fiber Crops Research Institute (ISFRI), Malang, Indonesia. Molecular analysis was done at the Plant Molecular Biology Laboratory (PMB Lab), Department of Agronomy and Horticulture, Faculty of Agriculture, Bogor Agricultural University, Bogor, Indonesia. The only surviving putative interspecific hybrids progenies (eight plants) between J. curcas as the female parent and red-flowered $J$. integerrima as the male counterpart (Asbani 2008) were used.

Observation of the morphological characters was performed to the parents and their interspecific hybrids to determine the inheritance of the characters from the parents to the progenies. The evaluated characters include the leaf shapes and colors, flowers, fruits, mature seeds, and the branching shape. Variations of morphological characters are photographed and documented to provide detail information.

\section{Primers for molecular characterization}

The putative interspecific hybrid progenies and their respective parents were used for identifying informative SSR, RAPD, and ISSR markers. The DNA samples were isolated from young leaves of the evaluated progenies and their respective parents. DNA samples were used as templates for PCR amplification using RAPD (5 primers), ISSR (3 primers) (Table 1) and SSR (9 loci) markers (Table 2). We have previously evaluated the effectiveness of these DNA markers for J. curcas (Saptadi et al. 2011).

\section{DNA extraction}

The DNA was extracted from all of the Jatropha leaf samples using the standard CTAB protocols (Doyle 1990). A total of $0.1 \mathrm{~g}$ fresh Jatropha leaf was homogenized in $500 \mu \mathrm{L}$ of extraction buffer (CTAB 2\%, $100 \mathrm{mM}$ Tris $\mathrm{HCl}$ $\mathrm{pH} 8,3.5 \mathrm{M} \mathrm{NaCl}$ ) and $1 \%$ polyvinylpolypyrrolidone (PVP). Leaf extract was then transferred into a $2.000 \mu \mathrm{L}$ microtube, $1.5 \% \beta$-mercaptoethanol was added, and after thoroughly mixing, the mixture was incubated at $65{ }^{\circ} \mathrm{C}$ for 90 minutes. Chloroform: isoamyl alcohol (24: 1) of the equal volume was added to the heated mixtures, and the mixture was shaken gently for $10 \mathrm{~min}$. The mixture was centrifuged at $8,000 \mathrm{rpm}$ for $8 \mathrm{~min}$ at room temperature, and the upper liquid phase was transferred to a new tube. After adding an equal volume of $2 \mathrm{M} \mathrm{NaCl}$ and a 0.6 time of isopropanol to the final volume, the mixtures were incubated at room temperature for 60 minutes. Subsequently, $80 \%$ cold ethanol was added to the mixture for as much as twice of the final volume. Subsequently, the final mixtures were incubated for 10 minutes and centrifuged at 10,000 rpm at room temperature for $15 \mathrm{~min}$. The DNA pellet was washed with $70 \%$ ethanol, dried and dissolved in $200 \mu \mathrm{L}$ TE buffer. Quantification of the DNA was done using a spectrophotometer and validated by running the DNA on an agarose gel electrophoresis. 
Table 1. List of primers used to generate RAPD and ISSR markers in the studies

\begin{tabular}{clcl}
\hline Primers & Sequences & Primers & Sequences \\
\hline RAPD & & ISSR & \\
OPC 10 & TGTCTGGGTG & UBC 810 & GAG AGA GAG AGA GAG AT \\
OPG 17 & ACGACCGACA & UBC 812 & GAG AGA GAG AGA GAG AA \\
OPG 18 & GGCTCATGTG & UBC 834 & AGA GAG AGA GAG AGA GYT \\
OPQ 11 & TCTCCGCAAC & & \\
OPV 17 & ACCGGCTTGT & & \\
\hline
\end{tabular}

Table 2. List of primer sets used to generate simple sequence repeat (SSR) markers in the studies

\begin{tabular}{|c|c|c|c|c|}
\hline Accessions & Primer sequences & $\begin{array}{l}\text { PCR product } \\
\text { (bp) }\end{array}$ & $\begin{array}{c}\text { Ta } \\
\left({ }^{\circ} \mathbf{C}\right)\end{array}$ & Repeat pattern \\
\hline EU586348 & $\begin{array}{ll}\mathrm{F} & \text { GGGCTGGGATTTTGTCTCTT } \\
\mathrm{R} & \text { GGCATGACCCTTGTGACTCT }\end{array}$ & 246 & 55 & (GT)12(AG) 23 \\
\hline EU586343 & $\begin{array}{ll}\mathrm{F} & \text { CATGAAGTTTGCTGGCAATG } \\
\mathrm{R} & \text { AAAGGTCATCTGGTAAAGCCATA }\end{array}$ & 129 & 54 & GT(4)..(GA)5 \\
\hline EF612741 & $\begin{array}{ll}\mathrm{F} & \text { GGCATTTCCTTGCATTTTCA } \\
\mathrm{R} & \text { CTGAGCAAACGGGGAAGTAA }\end{array}$ & 489 & 55 & (TAA)10..(A)8 \\
\hline EF612739 & $\begin{array}{ll}\mathrm{F} & \text { GGCATTTCCTTGCATTTTCA } \\
\mathrm{R} & \text { GAAGGGCAGAGGCTTCACTA }\end{array}$ & 620 & 54 & (TAA)10..(A)8 \\
\hline EU099518 & $\begin{array}{ll}\mathrm{F} & \text { CTCATGAACAACAAGAATTT } \\
\mathrm{R} & \text { CAGATTCTAATGAAGGTACG }\end{array}$ & 137 & 55 & (TA)3(TG)18.. (TA)6 \\
\hline EU099522 & $\begin{array}{ll}\mathrm{F} & \text { CAAATAGATTCCTCAATCC } \\
\mathrm{R} & \text { GGGACCCAAAGAAACAAT }\end{array}$ & 122 & 44 & (TC) 16 \\
\hline EU099524 & $\begin{array}{ll}\mathrm{F} & \text { ATTCATGTACCAGTCAAGTC } \\
\mathrm{R} & \text { TGCTAAAACTCTGGTTCTCT }\end{array}$ & 109 & 44 & (C)6..(C)5(AC)5 \\
\hline AF469003 & $\begin{array}{ll}\mathrm{F} & \text { CATCTTATGAAACTGTCGTT } \\
\mathrm{R} & \text { TACTTACAAAGAAAGCGAGA }\end{array}$ & 145 & 45 & $(\mathrm{TAA}) 8$ \\
\hline EU586349 & $\begin{array}{ll}\mathrm{F} & \text { CAAAATAAGTCGAAACAAAC } \\
\mathrm{R} & \text { TATAGGCTCTTGCATAAATC } \\
\end{array}$ & 143 & 44 & (A)6..(A)8..(CA)4 \\
\hline
\end{tabular}

Note: $\mathrm{F}=$ forward primer, $\mathrm{R}=$ reverse primer, $\mathrm{Ta}=$ annealing temperature

\section{Amplification and separation of amplicon}

PCR amplification for the target sequences was performed in a total volume of $25 \mu \mathrm{L}$ containing $0.2 \mu \mathrm{M}$ of the evaluated primers, $1.25 \mathrm{U}$ Taq polymerase (Real Biotech Corporation), 1x PCR buffer, $0.1 \mu 1$ of $10 \mathrm{mM}$ dNTP mix, and $1 \mu \mathrm{l}$ of DNA template. The cycle used to amplify the SSR markers include one cycle of denaturation at $95^{\circ} \mathrm{C}$ for $5 \mathrm{mins} ; 36$ cycles of denaturation at $94^{\circ} \mathrm{C}$ for $30 \mathrm{~s}$, annealing at the suitable temperatures for each primer for $30 \mathrm{~s}$, elongation at $72^{\circ} \mathrm{C}$ for $1 \mathrm{~min}$. One cycle of primer extension at $72^{\circ} \mathrm{C}$ for 5 mins was added at the end of the PCR steps. The steps for RAPD markers amplification include one denaturation cycle at $94^{\circ} \mathrm{C}$ for 3 mins followed by 45 cycles, each at $94^{\circ} \mathrm{C}$ for $45 \mathrm{~s}, 36^{\circ} \mathrm{C}$ for $30 \mathrm{~s}$ and $72^{\circ} \mathrm{C}$ for $2 \mathrm{~min}$. A final primer extension at $72^{\circ} \mathrm{C}$ for 7 mins was added at the end of PCR cycles. The DNA amplification conditions for ISSR is as follow: one denaturation cycle at $94^{\circ} \mathrm{C}$ for 4 min followed by 35 cycles, each at $92^{\circ} \mathrm{C}$ for $30 \mathrm{~s}$, Ta of each primer for $1 \mathrm{~min}, 72^{\circ} \mathrm{C}$ for 2 mins and a final extension at $72^{\circ} \mathrm{C}$ for 7 mins.

The PCR amplified DNA of either the RAPD or the ISSR markers were fractionated by agarose gel electrophoresis (1\%), visualized by ethidium bromide staining, and observed under UV transluminescent. One kb DNA ladder was used as the size markers of the PCR amplicon. SSR markers were fractionated in a $6 \%$ polyacrylamide gel electrophoresis (PAGE) using standard procedures (Saptadi et al. 2011). PAGE separation was performed in a Dedicated Height Sequencer (Cole-Palmer) using $1 \mathrm{X}$ TBE buffer at a constant voltage of $1100 \mathrm{~V}$ for 3 hours. The 100 bp DNA ladders were used to estimate the size of the SSR amplicon, and the PAGE results were visualized using silver staining.

\section{Data analysis}

The SSR, RAPD and ISSR markers were scored based on the present or absent of the amplicons for the evaluated individual using the electropherograms. For each of the amplicon sizes in the SSR, RAPD and ISSR analysis, score " 1 " was given if the DNA band present and score " 0 " if the DNA band absent. A scoring table was created to facilitate the comparison of DNA banding patterns between parent and interspecific hybrids; binary data was created from the marker scores and used to calculate the genetic distances among individuals. We calculated dissimilarity matrix based on the score data for the combined SSR, RAPD, and ISSR markers and used simple matching dissimilarity index to estimate genetic distance. The iterations for bootstrap analysis were set at 10,000 and the weighted Neighbour Joining approach was used to do the tree construction. Dissimilarity Analysis and Representation for WINDOWS (DARwin) software version 6.05 (Perrier and 
Jacquemoud-Collet 2006) was used to calculate the dissimilarity matric, bootstrap, and tree construction for the evaluated Jatropha accessions.

\section{RESULTS AND DISCUSSION}

\section{Morphological characterizations}

All individuals of the putative interspecific hybrids grow vigorously, able to produce flowers and show intermediate morphological characteristics between the two Jatropha parents. Some of the putative interspecific hybrids follow the male (J. integerrima) parental characteristics for the branch, stem, inflorescence and leaf pigmentation, petiole and flower stalk characters. The seed formation in the putative interspecific hybrids also similar to the flowering and fruiting characters of the male parent. The stem in the putative interspecific hybrids resembles the male parent which was sturdier than the female J. curcas. Leaf shapes resemble the female parent, but leaf sizes were intermediate between the two parents. The fruit shape and size were also midway between those of the two parents (Table 3; Figure 1).

\section{Characterization using RAPD and ISSR markers}

Five RAPD and three ISSR primers were used to generate either RAPD or ISSR markers (Table 1, Table 4). Using total DNA isolated from $\mathrm{P}_{1}$ and $\mathrm{P}_{2}$ genomic DNA, the random primers OPQ 11, OPC 10, OPG 17 and OPG18 generated either one or two RAPD marker loci (Table 4). On the other hand, random primer OPV17 only generated one RAPD marker for $\mathrm{P}_{1}$ parent and absence for $\mathrm{P}_{2}$ (Table 4). Although capable of amplifying two RAPD marker bands (2 loci) from $\mathrm{P}_{1}$ and a single band (1 locus) from $\mathrm{P}_{2}$ (Table 4), the putative interspecific hybrids only have marker bands from the $\mathrm{P}_{1}$ (OPG 17-1 and OPG 17-3 loci) and absence for the $\mathrm{P}_{2}$ origin (OPG 17-2 locus), indicating the genotype of the $\mathrm{P}_{2}$ for OPG 17-2 locus was probably (+/-). The OPG 18 primer was capable of amplifying one RAPD marker band (1 locus, OPG 18-3) from $\mathrm{P}_{1}$ and two bands (2 loci, OPG 18-2 and OPG 18-3) from $\mathrm{P}_{2}$ (Table 4). However, all the progenies yielded RAPD marker band (1 locus, RAPD 18-1) which was absent in the $\mathrm{P}_{1}$ and $\mathrm{P}_{2}$ parents. Hence, OPG 17 and OPG 18 primers were not usable for detecting the putative interspecific hybrids of $J$. curcas $\mathrm{x} J$. integerrima. Meanwhile, OPQ 11 primer generated two DNA marker bands in either $\mathrm{P}_{1}$ (OPQ 11-2 and OPQ 11-4) or the $\mathrm{P}_{2}$ parents (OPQ 11-1 and OPQ 113). Moreover, the OPC 10 primer generated a single RAPD marker for $\mathrm{P}_{1}$ (OPC 10-1) and two RAPD markers for $\mathrm{P}_{2}$ (OPC 10-2 and OPC 10-3). The putative interspecific hybrids of $J$. curcas $\mathrm{x} J$. integerrima also carry allele combinations for the loci derived from both parents (Table 4). Therefore, only two out of five RAPD primers evaluated were useful for detecting the putative interspecific hybrid progenies.

Two of the evaluated ISSR primers (UBC 810 and UBC 834) yielded monomorphic markers in all the tested individuals, and one ISSR primer (UBC 812) did not produce amplified DNA (Table 4). Therefore, the evaluated ISSR primers in this study were useless for finding the Jatropha interspecific hybrids.

\section{Characterization using SSR markers}

PCR amplification using eight pairs of the evaluated SSR primers yielded amplicons in the putative interspecific hybrids and their parents while one primer pairs (EU099524) resulted in no amplicon for the male parent DNA template. The detected number of loci were 1 to 3 loci for the parents and 1 to 5 loci for the putative interspecific hybrid populations. Most of the alleles associated with the putative interspecific hybrids were originated from either the parents, except for two alleles. The irregular allele was generated by the SSR primer of AF469003. These irregular SSR alleles were found in the putative interspecific hybrid (IH) \#6. Most of the generated SSR were either polymorphic against the two parents or among parents and their interspecific hybrids.

Table 3. Evaluation results of various morphological characters among the Jatropha curcas $\left(\mathrm{P}_{1}\right)$, J. integerrima $\left(\mathrm{P}_{2}\right)$ and eight putative interspecific hybrid progenies $\left(\mathrm{F}_{1}\right)$

\begin{tabular}{|c|c|c|c|}
\hline Characters & $\mathbf{P}_{1}($ J. curcas $)$ & Interspecific hybrids & $\mathbf{P}_{2}(J$. integerrima $)$ \\
\hline Leaf & $\begin{array}{l}\text { Spiral, cordate, palmately with } 5 \\
\text { deep lobes, dark green }\end{array}$ & $\begin{array}{l}\text { Spiral, cordate with } 5 \text { shallow lobes, } \\
\text { dark green, }\end{array}$ & $\begin{array}{l}\text { Spiral, obovate with } 3 \text { shallow lobes, } \\
\text { dark green }\end{array}$ \\
\hline Petiole & Long, non-pigmented & Medium, light purple pigment & Short, strong purple pigment \\
\hline Stem & Stout, thick bark, frangible & Slim, thin bark, strong, woodier & Slim, thin bark, strong, woodier \\
\hline Branching & Many, pointing up & Many leads to side & Many leads to side \\
\hline Flower & $\begin{array}{l}\text { Small size, greenish-yellow } \\
\text { petals rolled on end, non- } \\
\text { pigmented stalk, light yellow } \\
\text { pollen }\end{array}$ & $\begin{array}{l}\text { Medium size, pink petals with light } \\
\text { roll on end, light purple pigmented } \\
\text { stalk and non-pigmented, yellow } \\
\text { pollen }\end{array}$ & $\begin{array}{l}\text { Big size, flat dark pink petals, purple } \\
\text { stalk, yellow pollen }\end{array}$ \\
\hline Inflorescence & $\begin{array}{l}\text { Cymose, unisexual, monoecious, } \\
\text { short non-pigmented stalk }\end{array}$ & $\begin{array}{l}\text { Cymose, unisexual, monoecious, long } \\
\text { light pigmented stalk }\end{array}$ & $\begin{array}{l}\text { Cymose, unisexual, monoecious, long } \\
\text { dark pigmented stalk }\end{array}$ \\
\hline Fruit & Green, big, drupaceous & $\begin{array}{l}\text { Green, medium, some pigmented, } \\
\text { shallow lobes }\end{array}$ & $\begin{array}{l}\text { Green with purple pigment, small with } \\
\text { deep lobes }\end{array}$ \\
\hline Seed & Big, black & Medium, black to brownish-black & Small, brown with a black dot \\
\hline
\end{tabular}


The EU099518 SSR primer pairs amplified the same allele (allele 2) for the $\mathrm{P}_{1}$, the $\mathrm{P}_{2}$, and in the seven out of eight putative $F_{1}$ interspecific hybrids (Table 5). Meanwhile, the EF612741 and EF612739 SSR primer pairs amplified allele 2 in the $P_{1}$ and allele 1 in the $P_{2}$ parents. However, the putative $F_{1}$ interspecific hybrids mostly carry the allele 1 from $\mathrm{P}_{2}$ parent. Moreover, the EU099524 SSR primer pairs amplified allele 1 and 2 in the $\mathrm{P}_{1}$ and no amplicon in the $\mathrm{P}_{2}$. PCR using the EU099524 SSR primer pairs from all the putative $F_{1}$ interspecific hybrids amplified the same allele 1 and 2 as in the $\mathrm{P}_{1}$ parent (Table 5).

The EU586343 and the EU586349 SSR primer pairs amplified allele 1 and 2 (EU586343) and allele 1,2, and 3 (EU586349) in the $\mathrm{P}_{1}$ (Table 5). On the other hand, the EU586343 and EU586349 SSR primer pairs amplified alleles 2 and 3 respectively in the $P_{2}$. The putative $F_{1}$ interspecific hybrids mostly carry the allele 1 and 2 (EU586343) and allele 1,2, and 3 (EU586349). Therefore, the generated SSR alleles of the EU586343 and the EU586349 primer pairs in the $\mathrm{P}_{1}$ and $\mathrm{P}_{2}$ parents segregated in the $F_{1}$ interspecific hybrid progenies (Table 5).
The following SSR primer pairs (Table 5) amplified allele 2 in the $\mathrm{P}_{1}$ and allele 1 in the $\mathrm{P}_{2}$ parents (AF469003), allele 2,3,5 in the $P_{1}$ and allele 1,4 in the $P_{2}$ (EU099522) and allele 1,3 in the $\mathrm{P}_{1}$ and allele $2,4,5$ in the $\mathrm{P}_{2}$ (EU586348). Moreover, the generated SSR alleles of the AF469003, the EU099522 and the EU586348 SSR primer pairs in the $P_{1}$ and $P_{2}$ parents were also segregated in the $F_{1}$ interspecific hybrid progenies (Table 5). Representative samples of the polymorphic SSR markers are presented in Figure 2.

\section{Genetic diversity of the evaluated Jatropha}

The value of genetic dissimilarity between the $\mathrm{P}_{1}(J$. curcas) and $\mathrm{P}_{2}$ (J. integerrima) based on all molecular markers was $66 \%$ (Table 6). The highest genetic dissimilarity score $(45 \%)$ resulted between $\mathrm{P}_{1}$ and $\mathrm{IH \# 1}$, and the lowest genetic similarity $(7 \%)$ resulted between IH\#3 and IH\#5 (Table 6). The mean values of genetic dissimilarity among $\mathrm{IH}$, among $\mathrm{IH}$ and $\mathrm{P}_{1}$, and among $\mathrm{IH}$ and $\mathrm{P}_{2}$ were $18 \%, 62 \%$, and $78 \%$, respectively.

Table 4. Scoring of the molecular markers generated by five RAPD and three ISSR primers for the parental $\left(\mathrm{P}_{1}\right.$ and $\left.\mathrm{P}_{2}\right)$ and the putative interspecific hybrids (8 individuals) of Jatropha curcas x J. integerrima.

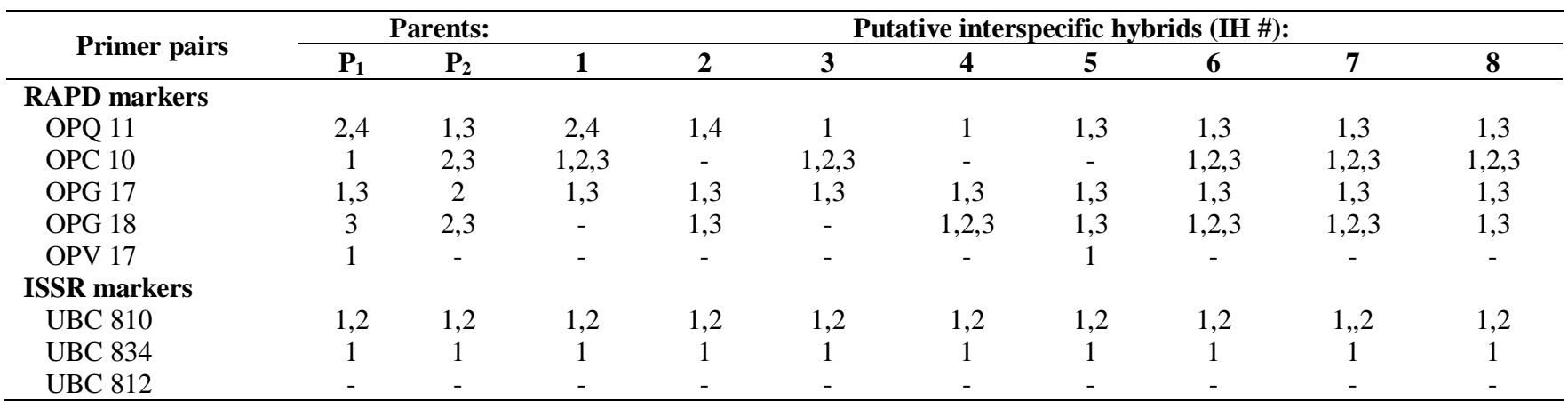

Note: Parental line $\mathrm{P}_{1}=J$. curcas; $\mathrm{P}_{2}=J$. integerrima and 1-8 $=$ the putative interspecific hybrid progenies. $--=$ No DNA band was detected. *Numbers showed the identity of the yielded PCR amplified products using the respective primers and the individual DNA template.

Table 5. Scoring of the molecular markers generated by nine SSR primer pairs for the parental $\left(\mathrm{P}_{1}\right.$ and $\left.\mathrm{P}_{2}\right)$ and the putative interspecific hybrids (8 individuals) of Jatropha curcas x J. integerrima.

\begin{tabular}{|c|c|c|c|c|c|c|c|c|c|c|}
\hline \multirow{2}{*}{ SSR primer pairs } & \multicolumn{10}{|c|}{ Individuals } \\
\hline & $\mathbf{P}_{1}$ & $\mathbf{P}_{2}$ & 1 & 2 & 3 & 4 & 5 & 6 & 7 & 8 \\
\hline EU586348 & $1,3^{*}$ & $2,4,5$ & $1,2,3,4$ & $1,3,5$ & $1,3,5$ & 2,4 & 3,5 & $1,3,5$ & 3,5 & 3,5 \\
\hline EU586343 & 1,2 & 2 & 1,2 & 1,2 & 1,2 & 1,2 & 1,2 & 1,2 & 1,2 & 1,2 \\
\hline EF612741 & 2 & 1 & 1 & 1 & 1 & 1 & 1 & 1 & 1 & 1 \\
\hline EF612739 & 2 & 1 & 2 & 1 & 1 & 1 & 1 & 1 & 1 & 2 \\
\hline EU099518 & 2 & 2 & 2 & 2 & 2 & 2 & 2 & 1 & 2 & 2 \\
\hline EU099522 & $2,3,5$ & 1,4 & $1,2,3,4,5$ & $1,2,3,4,5$ & $1,2,3,4,5$ & $1,2,3,4,5$ & $1,2,3,4,5$ & $1,2,3,4,5$ & $1,2,3,4,5$ & $1,2,3,4,5$ \\
\hline EU099524 & 1,2 & -- & 1,2 & 1,2 & 1,2 & 1,2 & 1,2 & 1,2 & 1,2 & 1,2 \\
\hline AF469003 & 2 & 1 & 1,2 & 1,2 & 2 & 1,2 & 1,2 & 3 & 1,2 & 2 \\
\hline EU586349 & $1,2,3$ & 3 & $1,2,3$ & $1,2,3$ & $1,2,3$ & $1,2,3$ & $1,2,3$ & $1,2,3$ & -- & 3 \\
\hline
\end{tabular}

Note: Parental line $\mathrm{P}_{1}=J$. curcas; $\mathrm{P}_{2}=J$. integerrima and 1-8 $=$ the putative interspecific hybrid progenies. $-=$ No DNA band was detected. *Numbers indicated the identity of the PCR amplified products yielded by PCR using the respective primers and the individual DNA template. 

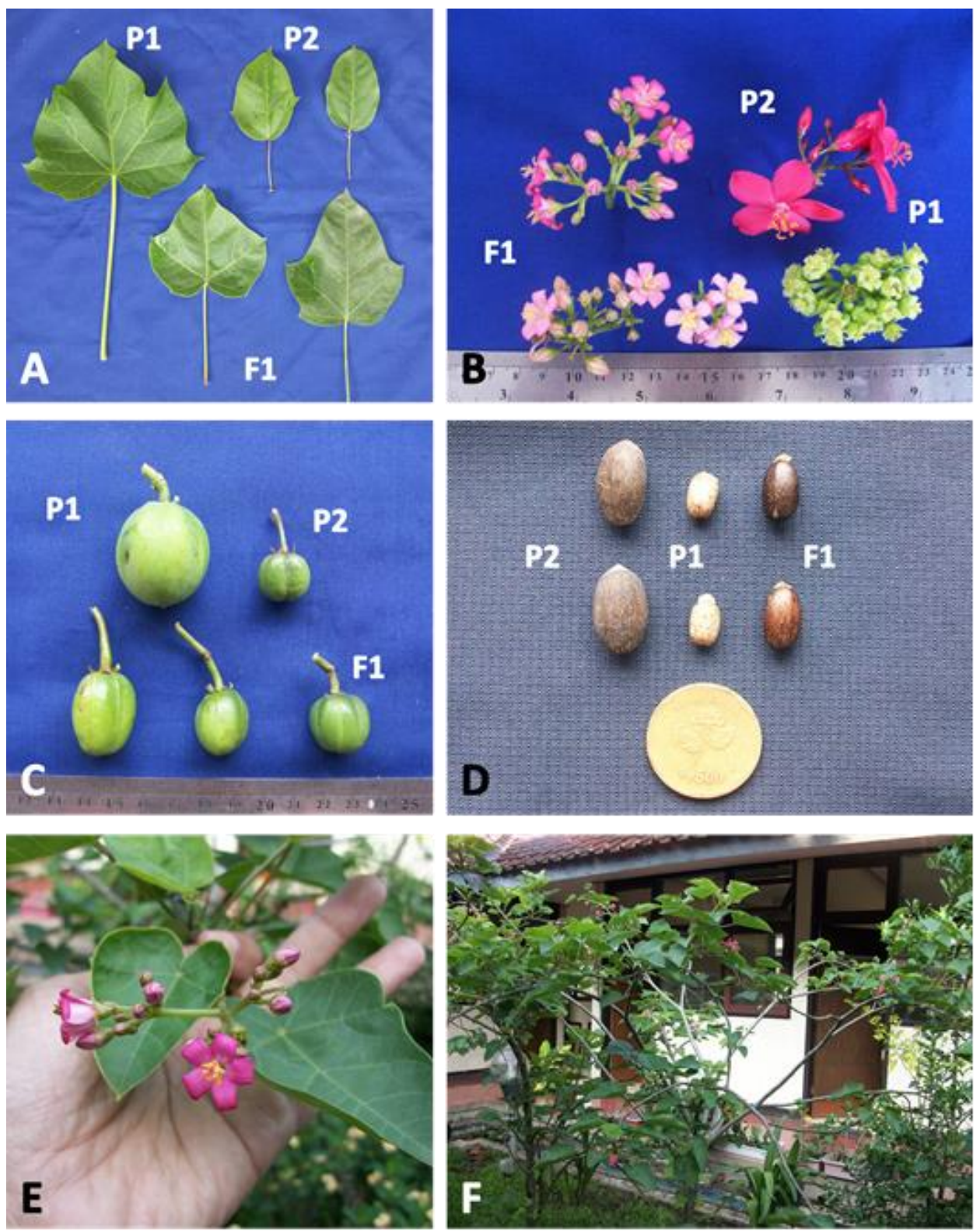

Figure 1. Result of morphological observation: (A) leaves, (B) flowers, (C) fruits, and (D) seeds of Jatropha curcas (P1), J. integerrima (P2), and their interspecific hybrids. (E) F1 inflorescence pigmentation, and (F) F1 branching

Table 6. The coefficient of genetic dissimilarity among Jatropha curcas, J. integerrima, and eight of their interspecific hybrid (IH) progenies. The dissimilarity coefficient was determined based on the result of genotyping using 9 SSR, 5 RAPD, and 3 ISSR marker

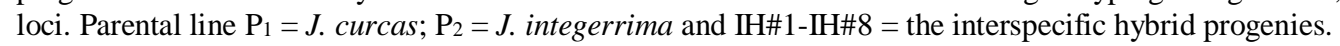

\begin{tabular}{|c|c|c|c|c|c|c|c|c|c|c|}
\hline & $\mathbf{P}_{1}$ & $\mathbf{P}_{\mathbf{2}}$ & IH\#1 & IH\#2 & IH\#3 & IH\#4 & IH\#5 & IH\#6 & IH\#7 & IH\#\# \\
\hline $\mathrm{P}_{1}$ & - & & & & & & & & & \\
\hline $\mathrm{P}_{2}$ & 0.66 & - & & & & & & & & \\
\hline IH1 & 0.45 & 0.18 & - & & & & & & & \\
\hline IH2 & 0.39 & 0.25 & 0.21 & - & & & & & & \\
\hline IH3 & 0.38 & 0.28 & 0.15 & 0.13 & - & & & & & \\
\hline $\mathrm{IH} 4$ & 0.39 & 0.26 & 0.21 & 0.11 & 0.2 & - & & & & \\
\hline IH5 & 0.39 & 0.26 & 0.28 & 0.07 & 0.16 & 0.11 & - & & & \\
\hline IH6 & 0.38 & 0.37 & 0.28 & 0.19 & 0,14 & 0.22 & 0.19 & - & & \\
\hline IH7 & 0.31 & 0.37 & 0.24 & 0.21 & 0.2 & 0.14 & 0.18 & 0.19 & & \\
\hline IH8 & 0.38 & 0.28 & 0.19 & 0.24 & 0.19 & 0.2 & 0.2 & 0.21 & 0.09 & - \\
\hline
\end{tabular}




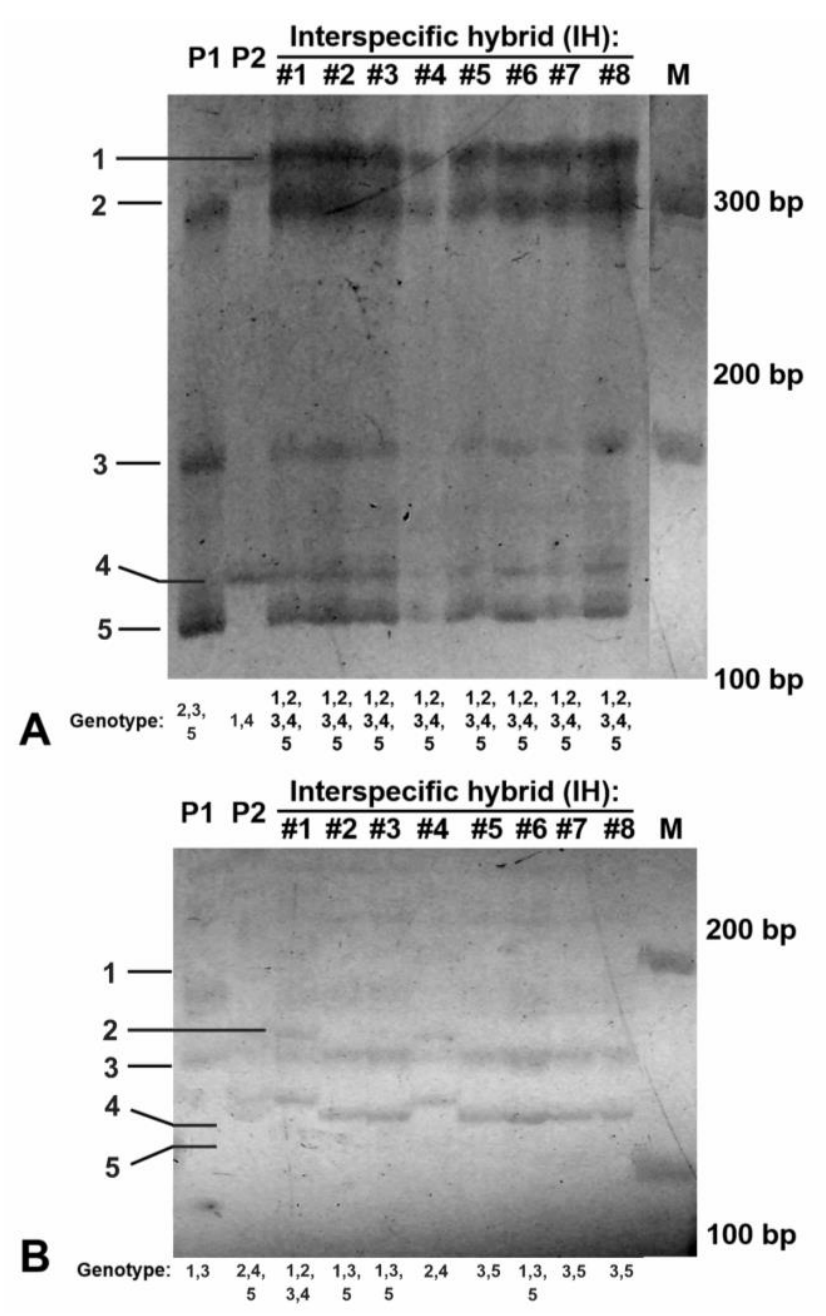

Figure 2. Electropherogram of DNA amplification result of eight $\mathrm{F}_{1}$ individuals (\#1-\#8) as results of crossing between Jatropha curcas $\left(\mathrm{P}_{1}\right)$ and $J$. integerrima $\left(\mathrm{P}_{2}\right)$ by using 2 SSR markers EU099522 (A) and EU586348 (B). M = 100 bp DNA markers.

Factorial and cluster analysis results among J. curcas $\left(\mathrm{P}_{1}\right)$, J. integerrima $\left(\mathrm{P}_{2}\right)$, and their interspecific hybrid $(\mathrm{IH})$ progenies constructed based on the dissimilarity coefficient values were presented in Figure 3.A and 3.B. Results of the factorial analysis showed that $J$. curcas $\left(\mathrm{P}_{1}\right)$ and $J$. integerrima $\left(\mathrm{P}_{2}\right)$ were indeed genetically distance-related (Figure 3.A). Moreover, the interspecific hybrid (IH) progenies were genetically in between the J. curcas $\left(\mathrm{P}_{1}\right)$ and $J$. integerrima $\left(\mathrm{P}_{2}\right)$, and there was less genetic diversity among the interspecific hybrids (Figure 3.A).

Figure 3.B. presented the result of cluster analysis among the evaluated Jatropha. Results of the cluster analysis showed that the Jatropha accessions were divided into three groups. The first group only has two members $\left(\mathrm{P}_{1}\right.$ and $\left.\mathrm{IH \# 1}\right)$, the second group consisted of $\mathrm{IH \# 2,} \mathrm{IH} \mathrm{\# 4,}$ and $\mathrm{IH} \# 5$, and the third group consisted of $\mathrm{P}_{2}$ and the rest of the interspecific hybrid (IH) progenies (Figure 3.B).

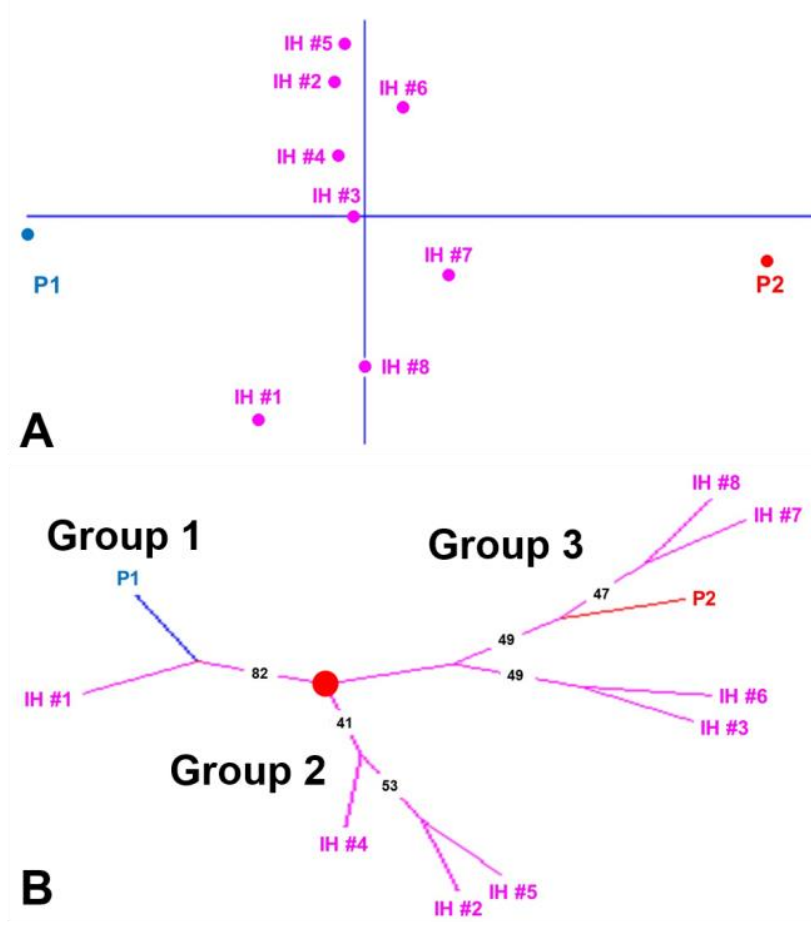

Figure 3. Results of the factorial and cluster analysis of $\mathrm{P}_{1}$ (Jatropha curcas), $\mathrm{P}_{2}$ (J. integerrima), and eight $\mathrm{F}_{1}$ interspecific hybrids (IH \#1 - IH\#8) between $\mathrm{P}_{1}$ and $\mathrm{P}_{2}$ constructed using the dissimilarity coefficient. The dissimilarity coefficient was estimated based on the genotyping results of the Jatropha using RAPD, ISSR and SSR markers.

\section{Discussion}

Although many scientists are able to generate interspecific hybrid progenies between $J$. curcas and $J$. integerrima and yielded hybrid progenies, the genetic materials were difficult to access by Indonesian scientists interested in working with the interspecific hybrids. Therefore, developing the interspecific hybrids locally in Indonesia is necessary. Sujatha and Prabakaran (2003) have successfully obtained ca. $9.3 \%$ seed formation out of the total interspecific hybridization between $J$. curcas and $J$. integerrima. Meanwhile, Dhillon et al. (2009) reported a $7.3 \%$ success rate for the same scheme of interspecific hybridizations. Hence, Asbani, (2008) has initiated the interspecific hybrid progenies between $J$. curcas and $J$. integerrima using locally available Jatropha sp. genetic materials from Indonesia.

As in previously reported interspecific Jatropha hybridizations (Sujatha and Prabakaran 2003; Dhillon et al. 2009), some degrees of sexual incompatibilities also exist in the interspecific hybridizations between $J$. curcas and $J$. integerrima from Indonesia (Asbani 2008). Fortunately, a limited number of fertile $F_{1}$ interspecific hybrids between the two Jatropha sp. were identified and grown to maturity. Those fertile interspecific progenies were kept as Jatropha collections at Indonesian Sweetener and Fiber Crops Research Institute (ISFRI), Malang, Indonesia. 
Although the remaining accessions of interspecific hybrids maintained at ISFRI showed many intermediate phenotypes between the two Jatropha parents, genetic analysis has not been done among the interspecific hybrids. Therefore, some of the putative hybrids could have been served progenies of the J. curcas. Therefore, before the putative interspecific hybrids be used for further breeding activities to improve Indonesian J. curcas, molecular characterizations are needed to confirm the identity of the putative interspecific hybrids.

Polymorphic markers (RAPD, ISSR, and SSR) for Indonesian $J$. curcas accessions have previously been identified (Saptadi et al. 2011). Therefore, these markers may potentially be used to validate the identity of putative interspecific hybrids. The RAPD and ISSR markers are dominant and multi-loci markers. On the other hand, the SSR marker is a co-dominant one. Therefore, the mode of inheritance for the RAPD, ISSR and SSR markers among putative interspecific $F_{1}$ hybrids are different. In the RAPD and ISSR markers, a single primer was used to amplify various loci in the genome. For each target locus, there would be either (+) or (-) DNA band as the allele. Therefore, the genotype of a certain locus in a diploid individual can either be homozygous $(+/+)$ or $(-/-)$ or a heterozygous $(+/-)$ and the RAPD marker scores for both the $(+/+)$ or $(+/-)$ genotypes were $(+)$ while for the $(-/-)$ genotype was (-).

Even though in previous report (Saptadi et al. 2011), the three ISSR primers were capable of generating polymorphic markers among $J$. curcas from Indonesia, they were not informative for identifying putative interspecific hybrids between $J$. curcas and $J$ integerrima. The first ISSR primer (UBC 812) did not produce any PCR amplicon in all tested Jatropha. The second ISSR primer (UBC 834) yielded one amplicon (1) from $\mathrm{P}_{1}$ (J. curcas), $\mathrm{P}_{2}$ (J. integerrima), and from the eight putative interspecific hybrids. The third ISSR primer (UBC 810) yielded two amplicons $(1,2)$ from $\mathrm{P}_{1}$ ( $J$. curcas), $\mathrm{P}_{2}(J$. integerrima), and from the eight putative interspecific hybrids. Therefore, the three ISSR primers cannot be used to confirm the identity of the putative interspecific hybrids.

Out of five RAPD primers previously reported capable of yielding polymorphic markers (OPQ 11, OPC 10, OPG 17, OPG 18 and OPV 17) (Saptadi et al. 2011), only OPC 10 was effective for confirming identity of the eight putative interspecific hybrids. The OPC 10 primers were (+) for amplicon 1 from $\mathrm{P}_{1}$ (J. curcas) and $(+)$ for both amplicon 2 and 3 from $\mathrm{P}_{2}$ (J. integerrima) parents. The amplicons from putative interspecific hybrids were either (+) for amplicon 1,2,3 (IH \#1, \#3, \#6, \#7 and \#8) or (-) for

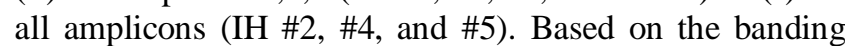
pattern of the interspecific hybrid progenies, the genotype of $\mathrm{P}_{1}$ parent was probably (+/-) for amplicon 1 , while the genotype of $\mathrm{P} 2$ parent was probably (+/-) for both amplicon 2 and 3 . Therefore, the expected RAPD banding patterns of the interspecific hybrids would either be $(+)$ for amplicon $1,2,3$; for amplicon 1,$2 ; 1,3 ; 2,3$ or (-) for all amplicons (no amplicon). As expected, two out of the five banding patterns which are (+) for amplicon 1,2,3 and (-) for all amplicon (no amplicon) were present in the eight progenies.

The number of identified loci by RAPD marker in this study was limited. However, we can use RAPD marker generated using OPC 10 to identify the interspecific hybrid progenies between $J$. curcas and J. integerrima. RAPD marker was a dominant marker (Williams et al. 1990) and the primer can be used to identify hybrid profiles by evaluating the co-inherited markers. Using RAPD markers, screening for putative hybrid genotypes can be faster and more cost-effective than evaluation using morphological characters. In some cases, there are some RAPD marker bands that appeared in the $F_{1}$ progenies but they were not found in their parents. Chromosome recombinations during meiosis could also lead to the loss of the RAPD priming sites, resulted in such anomaly in the RAPD markers among parents and their disappearance in the $F_{1}$ progenies and vice versa (Tyagi et al. 1992).

The primers to generate SSR markers used in this study were developed using J. curcas genome, and they were validated and informative against Indonesian accessions of J. curcas (Saptadi et al. 2011). The SSR markers were also tested for their cross-species amplification potential to other Jatropha species. The results those studies confirmed that the evaluated SSR markers were also informative for Jatropha sp. ( Saptadi et al. 2011; Sudheer et al. 2011).

To generate SSR marker, a pair of primers were used to amplify a target locus in the genome. For each target locus, there could be many sizes of amplified DNA bands as the alleles from different individuals. The genotype of a diploid individual can either be homozygous $(1 / 1)$ or $(2 / 2)$ or a heterozygous $(1 / 2)$ and the SSR marker scores for the $1 / 1$ genotype was 1 , for the $2 / 2$ genotype was 2 , for the $1 / 2$ genotype was 1,2 .

Out of nine SSR primer pairs used, three were effective for confirming identity of the eight putative interspecific hybrids (EU586348, EU099522, and AF469003). The EU586348 primers generated amplicon 1,3 from $\mathrm{P}_{1}(J$. curcas) and amplicon 2,4,5 from $\mathrm{P}_{2}$ (J. integerrima) parents. The amplicons from putative interspecific hybrids were either 1,2,3,4,5 (IH \#1), 1,3,5 (IH \#2, \#3, \#6), 2,3,4 (\#4), or 3,5 (\#5, \#7, \#8). The EU099522 primers generated amplicon 2,3,5 from $\mathrm{P}_{1}$ (J. curcas) and amplicon 1,4 from $\mathrm{P}_{2}$ (J. integerrima) parents. The amplicons from putative interspecific hybrids were all $1,2,3,4,5$ which are the combine alleles of the $\mathrm{P}_{1}$ and $\mathrm{P}_{2}$ parents. The AF469003 primers generated amplicon 2 form $\mathrm{P}_{1}$ (J. curcas) and amplicon 1 from $\mathrm{P}_{2}$ (J. integerrima) parents. The amplicons from putative interspecific hybrids were either 1,2 (IH \#1, $\# 2$, \#4, \#5 and \#7) which are the combine alleles of the $P_{1}$ and $\mathrm{P}_{2}$ parents; 2 (IH \#3, \#8) or 3 (IH \#6). Hence, out of nine SSR loci previously reported capable of yielding polymorphic markers (Saptadi et al. 2011), only three primer pairs were effective for confirming identity of the eight putative interspecific hybrids.

Among the 9 SSR primers used, the primers EU099522 and EU586348 were most informative primers because they produce most amplification bands, polymorphic for the parent and co-inherited in F1 individuals. The generated alleles from those primers segregated following 
normal Mendelian genetics in the $F_{1}$ generation. If the alleles for the SSR marker are polymorphic for the parent genome and they were co-inherited in the interspecific $F_{1}$ hybrid progenies, then the progenies can be used for genetic inheritance analysis (Kang et al. 2011). The SSR marker amplified using EU586343 was not informative because the allele was monomorphic for $J$. curcas and $J$. integerrima.

The genetic distance between $J$. curcas and $J$. integerrima was closer than that of other Jatropha species. Finding in this research confirmed the previous report about the existence of a correlation between the rate of success in interspecific hybridization and genetic distances among the parents. The previous report indicated that the hybridization success among plant species of the same genus depended on their genetic distance (Sudheer et al. 2009; Kumar Yadav et al. 2011). The previous report also proposed the success of interspecific hybrid depends on the use of $J$. curcas as the female parents (Sujatha and Prabakaran 2003; Dhillon et al. 2009).

Genetic diversity between $F_{1}$ ranged from 7 to $28 \%$ with an average of $18 \%$ indicated the low variation among crossbreeds. The hybrid plants grouped closer to the $J$. curcas parent $\left(\mathrm{P}_{1}\right)$ are individual \#1, \#2, \#3, \#4, \#5 and \#8, while hybrid individual \#6 is closer to $J$. integerrima parent $\left(\mathrm{P}_{2}\right)$ as presented in Figure 3.B. Those groupings were also supported with results of the SSR marker analysis. The SSR markers used in this study were developed using $J$. curcas genome. However, our results were in contrast to those of Dhillon et al. (2009), who reported J. curcas was more distantly related to the interspecific progenies. Our further evaluation indicated the grouping based on the molecular marker analysis was not complementary to those based on morphological characters.

The RAPD, ISSR, and SSR marker evaluation in this experiment aimed at obtaining effective molecular markers for the interspecific hybrid identification among interspecific progenies of $J$. curcas $\times J$. integerrima. Validation of the progeny identity using the selected molecular markers could be done in a more accurate way and a shorter period compare to the use of phenotypes. Moreover, screening for the interspecific hybrid progeny could also be done at the seedling level.

Several desirable characters are found among the interspecific hybrid progenies between $J$. curcas and $J$. integerrima parents. The desirable characters include all year flowering, resistance to major insects (thrips and mites) probably because of differences in trichome densities, leaf thickness, and leaf antixenosis or antibiosis compounds (Asbani 2008). Moreover, the hybrid progenies of $J$. curcas $\times J$. integerrima evaluated in this research showed vigorous stature and capable of producing normal flower (fertile). Phenotypic characters of the interspecific hybrids were intermediate between those of J. curcas and $J$. integerrima parents. However, for the stem characters, most of the interspecific hybrid progenies exhibited the characters of J. integerrima. Such observation validated the identity of progenies as interspecific hybrids. The intermediate character in the $\mathrm{F}_{1}$ individuals further confirmed that they were the results of hybridization between $J$. curcas and J. integerrima.

This study was the first using SSR markers for the identification of interspecific $\mathrm{F}_{1}$ hybrids between $J$. curcas and $J$. integerrima from Indonesia. The selected markers found in this study can be used to support Jatropha breeding program in Indonesia. However, more evaluations are necessary for studying linkage among the markers and the desired traits or phenotypes. Moreover, we have proven that interspecific hybrids between $J$. curcas $\mathrm{x} J$. integerrima accessions from Indonesia can be regenerated and fertile interspecific hybrids found. Therefore, generating $F_{2}$ progenies and subsequent advance generation from the interspecific $F_{1}$ hybrids should be possible. Our preliminary observation among the open-pollinated $F_{2}$ progenies derived from the hybrids showed the flowers and leaf morphological characteristics of $J$. curcas and the partial pigmentation character of $J$ integerrima. Subsequently, the confirmed interspecific $F_{1}$ hybrids may also be used to introgress genes controlling desired characters from $J$. integerrima into the $J$. curcas genetic background through backcross breeding. The introgression of such genes into J. curcas genomes will widen their genetic diversity.

Based on the overall evaluation results, the eight F1 progenies derived from $J$. curcas $\times J$. integerrima hybridizations were most probably the interspecific F1 hybrids between the two Jatropha parents. The confirmed identity of the eight $F_{1}$ progenies as interspecific hybrids between $J$. curcas $\times J$. integerrima was based on the presence of a number of phenotypic characters from both parents in the $F_{1}$ progenies and by similarity of the molecular marker banding patterns among the parents and the $F_{1}$ progenies. Among the evaluated molecular markers, the ISSR primers and the majority of either RAPD and SSR primers were not able to generate marker for confirming the identity of $F_{1}$ progenies as interspecific hybrids between $J$. curcas $\times J$. integerrima. However, the RAPD primer OPC 10 and the SSR primers AF469003, EU099522 and EU586348 were able to generate polymorphic markers in the Jatropha parents and their F1 progenies. Therefore, these four primers were able to generate usable markers for confirming the identity of F1 progenies as interspecific hybrids between $J$. curcas $\times J$. integerrima. The evaluated interspecific $\mathrm{F}_{1}$ progenies of $J$. curcas $\times J$. integerrima hybridizations are potentially useful to increase genetic diversity of $J$. curcas and support its breeding program in Indonesia.

\section{ACKNOWLEDGMENTS}

We sincerely thank Ministry of Agriculture, Agency for Agricultural Research and Development (AARD), the Republic of Indonesia for the KKP3T project which provides partial funding to this research. 


\section{REFERENCES}

Acquaah G. 2007. Principles of Plant Genetics and Breeding. Blackwell Publishing, Oxford UK.

Alam M, Islam M, Begum S. 2015. Grow out test and determination of physical characteristics of seed of rice landraces. Intl J Agric Res Innov Technol. 5 (1): 15-21.

Asbani N. 2008. Interspecific hybridization of Jatropha curcas L. and Jatropha integerrima Jaeq. for mites and thrips resistant crops. Pros Lokakarya Nasional III Inovasi Teknologi Jarak Pagar untuk Mendukung Program Desa Mandiri Energi 2008: 96-102. [Indonesian]

Banjanac T, Đurović S, Jelić M, Dragićević M, Mišić D, Skorić M, Živković JN, Šiler B. 2019. Phenotypic and genetic variation of an interspecific Centaurium hybrid (Gentianaceae) and its parental species. Plants 8 (7).

Conceição LDHCS, Belo GO, Souza MM, Santos SF, Cerqueira-Silva CBM, Corrêa RX. 2011. Confirmation of cross-fertilization using molecular markers in ornamental passion flower hybrids. Genet Mol Res 10 (1): 47-52.

Dhillon RS, Hooda MS, Jattan M, Chawla V, Bhardwaj M, Goyal SC 2009. Development and molecular characterization of interspecific hybrids of Jatropha curcas $\times J$. integerrima. Indian J Biotechnol 8 . 384-390.

Divakara BN, Upadhyaya HD, Wani SP, Gowda CLL. 2010. Biology and genetic improvement of Jatropha curcas L.: A review. Appl Energy. 87 (3): 732-742

Doyle J. 1990. Isolation of plant DNA from fresh tissue. Focus (Madison). [accessed 2017 May 1] 12: 13-15.

Gomes RA, Gurgel F de L, Peixoto L de A, Bhering LL, da Cunha RNV, Lopes R, Pina AJ de A, Veiga AS. 2014. Evaluation of interspecific hybrids of palm oil reveals great genetic variability and potential selection gain. Ind Crops Prod 52: 512-518

Gomez SM, Denwar NN, Ramasubramanian T, Simpson CE, Burow G Burke JJ, Puppala N, Burow MD. 2008. Identification of peanut hybrids using microsatellite markers and horizontal polyacrylamide gel electrophoresis. Peanut Sci 35 (2): 123-129.

Hartati RS, Setiawan A, Heliyanto B, Pranowo D, Sudarsono. 2009. Morphologies and yield performances of 60 selected genotypes of physic nut (Jatropha curcas L.) at Pakuwon experimental station, Sukabumi. Jurnal Littri 15 (4): 152-161. [Indonesian]

Hartati RS, Setiawan A, Heliyanto B, Sudarsono. 2012. Genetic variability, heritability, and correlation among characters of 10 selected genotypes of physic nut (Jatropha curcas L.) 18 (2): 74-80.

Heller J. 1996. Physic nut Jatropha curcas L.promoting the conservation and use of underutilized and neglected crops. Institute of Plant Genetics and Crop Plant Research, Gatersleben/ International Plant Genetic Resources Institute, Rome. https:

Hirose T, Ujihara A, Kitabayashi H, Minami M. 1993. Morphology and identification by interspecific hybrids in buckwheats isozyme analysis Fagopyrum 13: 25-30.

Huang SC, Tsai CC, Sheu CS. 2000. Genetic analysis of Chrysanthemum hybrids based on RAPD molecular markers. Bot Bull Acad Sin. 41 : 257-262.

Iqbal A, Sadaqat HA, Khan AS, Amjad M. 2011. Identification of sunflower (Helianthus annuus, Asteraceae) hybrids using simplesequence repeat markers. Genet Mol Res 10 (1): 102-106

Kaneko Y, Bang SW. 2014. Interspecific and intergeneric hybridization and chromosomal engineering of Brassicaceae crops. Breed Sci 64 (1): 14-22.

Kang JH, Kim YK, Park JY, An CM, Nam MM, Byun SG, Lee BI, Lee JH, Choi TJ. 2011. Microsatellite analysis as a tool for discriminating an interfamily hybrid between olive flounder and starry flounder. Genet Mol Res 10 (4): 2786-2794.

Kumar Yadav H, Ranjan A, Asif MH, Mantri S, Sawant SV, Tuli R. 2011 EST-derived SSR markers in Jatropha curcas L.: Development, characterization, polymorphism, and transferability across the species/genera. Tree Genet Genomes 7 (1): 207-219.

Lakshminarayana M. Sujatha M. 2001. Screening of Jatropha species against the major defoliators of castor (Ricinus communis L.). J Oilseeds Res 18: 228-230.
Moose SP, Mumm RH. 2008. Molecular plant breeding as the foundation for 21 st century crop improvement. Plant Physiol 147 (3): 969-977.

Pattanaik A, Lakshmana Reddy DC, Ramesh S, Chennareddy A. 2018. Comparison of traditional grow-out test and DNA-based PCR assay to estimate F1 hybrid purity in cauliflower. Curr Sci 115 (11): 20952102.

Perrier X, Jacquemoud-Collet J. 2006. DARwin Software [Internet]. http: //darwin.cirad.fr/darwin

Pershina LA, Trubacheeva N V. 2017. Interspecific incompatibility in the wide hybridization of plants and ways to overcome it. Russ J Genet Appl Res 7 (4): 358-368.

Pollegioni P, Woeste K, Mugnozza GS, Malvolti ME. 2009. Retrospective identification of hybridogenic walnut plants by SSR fingerprinting and parentage analysis. Mol Breed 24 (4): 321-335.

Raju AJS, Ezradanam V. 2002. Pollination ecology and fruiting behaviour in a monoecious species, Jatropha curcas L. (Euphorbiaceae). Curr Sci 83 (11): 1395-1398

Rao SK, Lakshminarayana G. 1987. Characteristics and composition of six newer seeds and the oils. Fett/Lipid 89: 324-326.

Ronis DH, Thompson AE, Dierig DA, Johnson ER. 1990. Isozyme verification of interspecific hybrids of Cuphea. Hortscience 25 (11): 1431-1434.

Saptadi D, Hartati RS, Setiawan A, Heliyanto B, Sudarsono. 2011. Development of simple sequence repeat markers for Jatropha spp. J Littri 17 (4): 140-149.

Saptadi D, Hartati RS, Setiawan A, Heliyanto B, Sudarsono. 2017. Genetic diversity of Indonesian physic nut (J. curcas) based on molecular marker. Agrivita 39 (60): 160-171.

Shasany AK, Darokar MP, Dhawan S, Gupta AK, Gupta S, Shukla AK, Patra NK, Khanuja SPS. 2005. Use of RAPD and AFLP markers to identify inter- and intraspecific hybrids of Mentha. J Hered 96 (5): 542-549.

Spooner D, Treuren R Van, Vicente MC De. 2005. Molecular Markers for Genbank Management. IPGRI Technical Bulletin No. 10. International Plant Genetic Resources Institute, Cali, Colombia.

Subroto G, Ujianto L, Yakop UM. 2018. Interspecific hybridization among vigna species to create new superior variety containing high protein and anthocyanin. Intl J Agric Sci 3: 34-39.

Sudheer PDVN, Pandya N, Reddy MP, Radhakrishnan T. 2009. Comparative study of interspecific genetic divergence and phylogenic analysis of genus Jatropha by RAPD and AFLP : Genetic divergence and phylogenic analysis of genus Jatropha. Mol Biol Rep 36 (5): 901-907.

Sudheer PDVN, Mastan SG, Rahman H, Ravi Prakash C, Singh S, Reddy MP. 2011. Cross-species amplification ability of novel microsatellites isolated from Jatropha curcas and genetic relationship with sister taxa: Cross-species amplification and genetic relationship of Jatropha using novel microsatellites. Mol Biol Rep 38 (2): 13831388 .

Sujatha M, Prabakaran AJ. 2003. New ornamental Jatropha through interspecific hybridization. Genet Resour Crop Evol 50: 75-82.

Thomasset M, Fernandez-Manjarrés JF, Douglas GC, Frascaria-Lacoste N, Raquin C, Hodkinson TR. 2011. Molecular and morphological characterization of reciprocal $\mathrm{F} 1$ hybrid ash (Fraxinus excelsior $\times$ Fraxinus angustifolia, Oleaceae) and parental species reveals asymmetric character inheritance. Intl J Plant Sci 172 (3): 423-433.

Van Tuyl JM. 1997. Interspecific hybridization of flower bulbs: A review. Acta Hortic 430: 465-476.

Tyagi B, Ahmad T, JR B. 1992. Cytology, genetics, and breeding of commercially important Mentha species. Curr Res Med Aromat Plants 14: 51-56.

Williams JG, Kubelik AR, Livak KJ, Rafalski JA, Tingey S V. 1990. DNA polymorphisms amplified by arbitrary primers are useful as genetic markers. Nucleic Acids Res 18 (22): 6531-6535.

Wu M, Jia X, Tian L, Baochun L. 2010. Rapid and Reliable Purity Identification of F1 Hybrids of Maize (Zea mays L.) Using SSR Markers. Mol Plant Breed 4 (3): 381-384.

Yi C, Zhang S, Liu X, Bui HT, Hong Y. 2010. Does epigenetic polymorphism contribute to phenotypic variances in Jatropha curcas L.? BMC Plant Biol 10 (1): 259 